\title{
On the Concept of Relative Rest in The Book of Rites • The Book of Music
}

\author{
Zhu Yuanbo \\ School of Chinese, Beijing Normal University, Zhuhai, Zhuhai, China
}

Keywords: the relationship between rites and music; rest; constancy; the spirit of suspicion; motion

\begin{abstract}
In traditional culture of China, since ancient times, there has been a pursuit of static state. Through the exploration of the concept of music, nature and interpersonal harmony in The Book of Rites - The Book of Music, the analysis of the complementary relationship between rites and music is conducted, this paper finds out that under the stable structure of internal and external interaction formed between rites and music, rest is not an absolute rest, but a relative rest that is unified with natural changes and social laws, and the spirit of constant harmony with all things. Nowadays, due to the spirit of suspicion of modern and pluralistic emphasis on motion, the stable structure formed by rites and music has been broken, and it is often challenged.
\end{abstract}

The Book of Rites • The Book of Music is a famous piece of The Book of Music. Naturally, it has a more accurate description of the expression of "music" and its core ideas, and there is no lack of explanation for the relationship between rites and music. "Music influences people's internal emotions and rites influences people's external behaviors". Music and rites, internally and externally echoes each other and complements each other. Music and rites can reach the harmony with nature in the two-dimensional environment of emotion and behavior, which is precisely consistent with the laws of nature. The harmony with nature refers to the so-called unity of nature and man, where people forget everything and be in harmony with eternal nature, change or not, so that people can reach relative rest. In traditional culture of China, since ancient times, there has been a pursuit of static state. The rest that the ancestors said is not motionless, nor a meditation that has evolved, and it is more about a pursuit of the mind. In "The way of Great Learning lies in the enlightenment of brilliant virtues, the remoulding of people, the pursuit of ultimate goodness", "the pursuit of ultimate goodness" is actually a rest, rest in a place, combined with the natural laws, the relationship of rites and music can indicate the rest for us.

\section{The Source of "Rest"-Music}

Music is basically the core of the concept of rest, and the source of rest. "Music is generated by the sounds, with emotion as its basis. With sadness, music is touching. With joy, music is soft. With happiness, music is exciting. With anger, music is rude. With respect, music is positive. With kindness, music is gentle. Music generate six different emotions, touched by external things." Human behavior resonates with nature, which is the so-called theory of unity between nature and human. People do not have the six emotions of sadness, happiness, joy, anger, respect, and love. It is caused by external things. "People are born in rest, which is the nature of human; It is also an instinct of nature to produce different emotions from the influence of external things. Instinctively perceive foreign objects, distinguish between different feelings, and form different preferences and dislikes." Similar to the "There is not difference of good and evil in human nature. The understanding of good and evil is the source of emotions" of Wang Yangming. Then, if it is affected by foreign objects, not be controlled, people alienated by things, people will have a desire for selfishness. Therefore, it is necessary to note that the important role of music is reflected here because of the sounds are emitted by these six emotions, and music is arranged according to sounds. Music is associated with people's hearts and emotions, and nature can affect people's hearts. "Rites is used to guide people's hearts. Music is used to reconcile people's emotions. The decree is used to unify people's behavior. Penalties are used to prevent evil behavior. The purpose of rites, music, decree, and penalty is the same, to unify the people and realize the governing of the country". It is 
precisely because music has the ability to communicate with the people that the ancestors hope that the music and the various emotions of the people will not be excessive, and that the fundamental role of music is the same as that of the rites, which is used to unify the people and to manage the society well. Therefore, similar to the education of Xue Ji (The Note of Learning), music also has the role of education, so music must be temperate, because the music is to neutralize the six emotions. "The country is stable, then formulates the six laws, reconciles the five sounds, accompanies the songs with musical instruments, and uses poetry to express praise, which is called music.” It can be seen here that Plato's attitude towards poetry is similar, and it also purifies in function, thus making the established order of social groups harmonious and stable. "Making people close to each other, forgetting sadness and sorrow is the performance of music; making people happy is the role of music”. People love each other, and harmonious coexistence is the main function of music. It can be seen that music is a more essential one, and it is directly from the heart. "Music connects to virtues." "Music means joy, which is indispensable in human nature." Music emphasizes the group's emotional communication, coordination and harmony to achieve the hierarchy and respect for seniority. It is a kind of internal guidance. To cultivate sentiment and shape emotions to shape virtue, and establish rationality and sociality in nature. However, music is not only originated from the heart but also communicates with nature. We can find that in the description of music, many passages will mention the changes of natural scenes, and the music and nature laws will be combined, and even more through music to mobilize the harmony of the four seasons to show the law governing everything. "Then use the sound to express, use the lyrics to decorate, hold the cognac to dance, decorate with the feathers, accompaniment with the fistula, and strive for the brilliance of the virtues, and encourage the harmony of the four seasons to show the truth of all things". It is not necessarily to mobilize the four seasons, but it should be an inner understanding of nature through music, thus transferring the natural sentiments to the people themselves. Music can make the good virtues, the ears are clear, the heart is calm, social conditions easy to transform, and the world is stable and better. Therefore, it is said that music makes people happy. But a man of noble character gets the righteousness from music, and the villain satisfies the lust from music." Naturally, music makes people connect with the nature. "Music is made to be close to the heaven, rites to be close to the earth." "Music is the harmony of heaven and earth", in fact, reaches the pursuit of the unity of human and nature, and the unity of human and things, which is also "the humanization of nature" by Li Zehou. Therefore, music is extensive, builds harmony and interaction with nature and society, paralyzing without friction, so as to provide living space for "rest".

\section{The Existing of "Stop"-the Complementary Music and Rites}

\subsection{The difference of rites and music}

The difference of rites and music lies in that rites is an external constraint. It is a mandatory code of conduct to distinguish people. Because of the distance, there is a difference, and people will have fear and create a concept of respect. And rites has become a social order and norm. It is made by people based on their inner imagination of beauty and rational thinking. But music is different. Music comes from the person itself. It is intrinsic, and it is the evolution of emotion, the emotional expression of people who are born in nature. It is not in opposition to human sensibility, and even obeys people's desire to some extent. It emphasizes not the separation of people, but the convergence of people, the harmonious coexistence between people, pleasure, happiness, and harmony, and it is actually love.

\subsection{The uniformity of rites and music}

Music is from the heart, and it is the humanization of nature. Therefore, although it is sentimental, it is not just a personal emotion, but a generalized law that is experienced when communicating with nature. There is an internalization. Music is from the heart so it influences people unconsciously. Music can make harmony and calmness just because it is separated form 
original emotional impulse, mediates the rationality and returns to the unaffected nature. In other words, rites and music are similar, suppressing and restricting the excessive desire of the person. From this perspective, the music is the same as the rites. For rites, you will feel happy when you are self-motivated. If you are self-suppressed, you will feel peace. The self-motivation of the rites and the self-suppression of the music are the same. The rites requires motivation, music requires to return to the nature, people can get elegant behaviors away from bad behaviors following formal constraints of rites, and the music can make people calm and settle away from the complicated desires because of the neutrality of inner feelings. An "elegant" and a "calm" have all played a role in purifying the people and educating the people. That is to say, to a certain extent, rites and music are unified.

\subsection{The complementarity of rites and music}

The difference and uniformity of rites and music form the complementarity of both. Rites teaches people to respect each other through different rites; music is to teach people to love each other through different melody. The social function of rites and music is the same, so the Ming Dynasty kings also have profit and loss in addition to inheritance. Therefore, the rites should have the characteristics of the times, and the name of the music must be consistent with the merits of the emperor. Although from the surface, rites pursues the difference between things, seeking differences, and music pursues the harmony of things, seeking the same. But the core of rites is respect, and the core of music is love. The common purpose of both is to maintain social harmony, order and stability. Therefore, there is the honor of moral achievement, the subtlety of skill achievement, the priority of meritorious work, and the inferiority of trivial tasks. The kings had the distinction between the top and the bottom of hierarchy, and then made the rites and music and made it to the world. So, too much respect will make the distance; too much music will lose the respect. "If music outweighs, the country will lose control; rites outweighs, the country will separate.” Therefore, rites and music shall complement each other. "Benevolence with love, courtesy with rites" will generate emotions and serious behaviors, which can reach the common aim. It can be seen that rites and music complement each other.

\subsection{Stop in Constancy}

The complementing relationship between rites and music, in fact, forms a stable human social structure. Rites separates equal distance in communication between people, and forms habitual behaviors in acquaintance society, which itself represents a kind of external constancy, and social norms followed by everyone. The norm itself will become a place where people stop, and it is this absolute stop that will form an invisible constraint, thereby restricting people from further action, even from the outside to the inside, planning a person's inner thinking, then this will form a relative rest. Because people do not dare to step beyond the threshold, and thinking is more constrained within the moral behavior, and lacks the ability to break through. This is not only the role of "rites", but also the "rites" itself can maintain the way of existence. Because for no matter what kind of system, the initial purpose is not used to break through, but hopes to maintain social stability for a long time. And music has similar effects to rites on the stability of society. Although different from rites, music appeals to the inner happiness of the human being. As the aesthetic sublimation in Attendance of "The Analects of Confucius", people are naturalized and melt into the unchanging world, see object from oneself and see oneself from object, free and endless happy. And the natural operation itself has its own laws. Everything has a law. When people's inner realm reaches the same level as the Tao, naturally, the change is only following an established law, then there is no change. This will enable people to follow the freedom without overstepping, because the person itself has become the embodiment of the law, and the heart is stable. Music is from the inside to the outside, rites from the outside to the inside, and they together form a binding shaping of people. Under the dual influence of rites and music, people tend to have a desire for the highest spiritual realm of their own, for a kind of rest, the so-called tranquil, so that move freely between the mind and the foreign objects, and it means to be constant, follow the laws, not pleased by external gains, and not saddened by personal losses. It is also one of the reasons why the Chinese value the spiritual 
inheritance. Stop in constancy, it is not motionless, but there is no difference between motion and motionless.

\section{Constancy and Modern Suspicion}

Unlike the permanence of constancy, modern suspicion itself is born out of the destruction of eternality. Since China's modern times, thought has been guided by modern Western society, and traditional values have been under attack. Rites and music have become the object of criticism, and they have lost their truth, and it is doubtful that their relationship can once again become the concept and value of the public.

As "The Dao is the underlying principle behind the creation of the myriad things. The order of the process giving rise to the myriad things began with the Dao producing a kind of generative force." in The Tao Teh King, "At first God created the heavens and the earth. The ground is empty chaos. The surface is in darkness. The Spirit of God runs on the water. God said that if there is light, there will be light. God sees the light is good, it separates the light and the darkness" in The Old Testament is similar. It can be seen that in the traditional society, there is always the only thing that acts as the unshakable core, which effectively curbs the people' s returning after the confusion and thinking about losing themselves and traveling. However, in the modern West, whether human beings can understand the origin and whether metaphysics can be regarded as a scientific examination is a suspicion of traditional values. In particular, Kant divides the world into phenomena and ontology, and believes that people cannot experience the ontological world, and can only experience the phenomenal world that can be seen, thus negating the scientific nature of metaphysics. This is invisibly wielding a hammer of doubt and reflection, wearing a load-bearing wall of traditional value and opening up the curtain of the stage of modern philosophy, and also opened the door to free thought. The diversity of ways of thinking, the diversity of behaviors, and the diversification of thought results are inevitable. After "God is dead", there is no absolute limit to the suspicion and the "Everything can be suspicious" creed has become the driving force for people's bold suspicion. Therefore, everything can be doubted, and everything is in an unrestricted perpetual motion. People become a part of the movement. In pursuit of speed, there must be a difference between speed and slowness. Binary opposition will destroy the stable structure in relative rest. Therefore, unless jumping out of the current society, this is almost irreversible negation for the realization of rest. As for suspicion, there is no doubt that no matter how the skeptics deny, it essentially has the eternal goal of seeking truth, and also constructing a new cornerstone of survival. However, it carries out a cyclical self-denial, which is also its absurd manifestation of inefficiency. Therefore, people cannot turn back in thought, and cannot continue to move forward, which is the typical spiritual appearance of this era.

\section{Conclusion}

Obviously, the concept of rest constructed by the relationship between rites and music, a spiritual realm that is parallel or even blended with the laws of nature, are also within the scope of modern suspicion, and are often becoming a concept rather than an idea. As a kind of spiritual realm, although there is commonality between constancy and suspicion, it is not sticking to the only one, but coexisting with changes. It is the harmony of life and the world, and even its inclusiveness can still be in harmony with suspicion. However, the problem lies in the fact that the suspicion of both sides of the contradiction has become the consensus of the modern society, so how to grow the constancy of seeking rest from motion in harmony?

\section{References}

[1] Yang Tianyu. Translation and Annotation of the Book of Rites [M]. Shanghai: Shanghai Chinese Classics Publishing House, 2004-07.

[2] Li Zehou. History of Ancient Chinese Thoughts [M]. Beijing: SDX Joint Publishing, 2015.4. 
[3] Li Zehou. Chinese Aesthetics• On Aesthetics [M]. Beijing: SDX Joint Publishing, 2015.10.

[4] [U.S] John Carroll the Wreck of Western Culture [M]. Ye Aning (Translator). Beijing: New Star Press, 2007.10.

[5] [UK] Bertrand Russell the History of Western Philosophy [M]. (Translator) He Zhaowu, Needham Joseph. Beijing: The Commercial Press, 2016.7. 